\title{
KIKUCHI-FUJIMOTO DISEASE- A RARE CAUSE OF CERVICAL LYMPHADENOPATHY- A CASE REPORT FROM WESTERN INDIA
}

\author{
Hemant R. Gupta1, Anish Deorao Kamble ${ }^{2}$
}

${ }_{1}^{1}$ Associate Professor, Department of General Medicine, Grant Medical College and Sir JJ Group of Hospitals, Mumbai, Maharashtra, India.

${ }^{2}$ Senior Resident, Department of General Medicine, Grant Medical College and Sir JJ Group of Hospitals, Mumbai, Maharashtra, India.

HOW TO CITE THIS ARTICLE: Gupta HR, Kamble AD. Kikuchi-Fujimoto disease- a rare cause of cervical lymphadenopathy- a case report from Western India. J. Evolution Med. Dent. Sci. 2018;7(44):4814-4816, DOI: 10.14260/jemds/2018/1072

\section{PRESENTATION OF CASE}

A female patient aged 17 years presented with complaints of fever since 25 days which was moderate to high-grade, associated with chills and mostly occurred in the evening, and lump in left lower part of the neck since 25 days. The lump was gradually increasing in size and was painful. She had no past history suggestive of SLE or tuberculosis.

On examination, patient was febrile with oral temperature of $38.8^{\circ} \mathrm{C}$ and pale. She had a palpable left posterior triangle node measuring $2.5 \times 1 \mathrm{~cm}$, which was mobile, firm in consistency and tender. No palpable lymph nodes were found in other parts of the body. Examination of cardiovascular system and respiratory system was normal. Neurological and per abdominal examination was normal.

\section{DIFFERENTIAL DIAGNOSES}

SLE, lymph node tuberculosis, lymphoma, metastatic carcinomas, sarcoidosis, infectious mononucleosis, Kimura's disease and Castleman's disease.

\section{CLINICAL DIAGNOSIS}

On the basis of history and examination, patient was suspected to have lymph node tuberculosis/ SLE/ KFD.

\section{PATHOLOGICAL DISCUSSION}

Lab investigations were as follows: Complete blood count revealed haemoglobin of $7.4 \mathrm{gm} \%$; total leucocyte count of $2400 / \mathrm{mL}$ with $30 \%$ neutrophils, $60 \%$ lymphocytes, 5\% eosinophils; platelet count was $248000 / \mathrm{mL}$; ESR was 52 $\mathrm{mm} / \mathrm{hr}$. Peripheral smear showed microcytic hypochromic anaemia with dimorphism and leukopenia. Reticulocyte count was $0.7 \%$. Liver function tests and renal function tests were normal. Blood tests for ANA, RA factor, Widal, Malaria antigen, HIV, HBsAG and anti-HCV were negative. Blood culture, urine culture and sputum culture were sterile. Mantoux test was negative. No acid fast bacilli was detected in ZN staining of sputum. Mycobacterium tuberculosis was not detected in Cartridge-based nucleic acid amplification test of sputum. Chest x-ray, abdominal ultrasound and ECG were normal.

Ultrasound of neck revealed multiple enlarged lymph nodes in bilateral levels II, III, left levels IV, V, largest

'Financial or Other Competing Interest': None.

Submission 05-09-2018, Peer Review 14-10-2018,

Acceptance 20-10-2018, Published 29-10-2018.

Corresponding Author:

Dr. Hemant R. Gupta,

\#203, Erica Dosti Acres Complex,

Near Antop Hill Bus Depot,

Waala (E), Antop Hill, Mumbai-400037,

Maharashtra, India.

E-mail: dr.hemantgupta@hotmail.com

DOI: $10.14260 /$ jemds $/ 2018 / 1072$

\section{(c) $(1) \ominus$}

measuring $2.7 \times 0.9 \mathrm{~cm}$ in left level $\mathrm{V}$ which appeared necrotic. Report of fine needle aspiration cytology of cervical lymph node showed polymorphous population of lymphocytes in various stages of transformation with numerous histiocytes with few lymphohistiocytic clusters seen in the background. There was no evidence of granuloma/ atypia/ malignancy. Findings suggested reactive lymphadenitis. Biopsy of cervical lymph node showed histiocytic necrotising lymphadenitis suggestive of KikuchiFujimoto disease. No acid-fast bacilli were detected on ZN staining. No malignancy. Mycobacterium tuberculosis was not detected in Cartridge based nucleic acid amplification test of lymph node biopsy specimen.

On the basis of history, examination findings and investigations, patient was diagnosed as a case of KikuchiFujimoto disease.

\section{DISCUSSION AND MANAGEMENT}

Patient was managed with oral prednisolone at a dose of $1 \mathrm{mg} / \mathrm{kg}$, which was gradually tapered. Patient improved symptomatically and a repeat ultrasonography of neck performed after 1 week showed a decrease in lymph node size.

Kikuchi-Fujimoto disease also known as histiocytic necrotising lymphadenitis was described in Japan in 1972 by Dr. Kikuchi[1] and in the same year by Dr. Fujimoto and colleagues.[2] The disease has a worldwide distribution, but is most frequent in Japanese and East Asian population. The exact incidence is unknown, but it is rare in India. The aetiology of the disease is not clearly understood. It probably has infective or autoimmune aetiology. Epstein-Barr virus,[3-5] herpes simplex virus, human herpes virus types 6,7 and 8,[5-7] HIV, HTLV[4] and parvovirus B19[4,8] are possible aetiological agents, but none has been confirmed. Infection with Yersinia enterocolitica,[9] Brucellosis,[10] Bartonella henselae[11] and Entamoeba histolytica[12] have been associated with development of KFD, but none has been established as aetiological agent. Many patients with KFD suffer from various autoimmune disorders with systemic lupus erythematosus being the most frequent.[13] There are reports of KFD patients developing SLE later in their life.[14] Certain human leukocyte antigen class II genes are more common in KFD patients. These genes are more common in Japanese population.[15]

KFD mostly affects young adults $<30$ yrs. old, male-tofemale ratio is almost equal, although some studies suggest female preponderance.[16] Familial cases of KFD have also been reported.[17] KFD commonly presents with multiple enlarged tender cervical lymph nodes associated with fever and flu-like symptoms. Skin is the most common extranodal organ affected. Skin manifestations include maculopapular rash, malar erythema, nodular lesions and plaques.[18] 
There is no confirmatory test for KFD. Majority of cases have a normal haemogram. Many cases have leukopenia, neutropenia and anaemia. ESR, LDH and ALT are elevated in some patients.[19-20] $25 \%$ cases of KFD have atypical lymphocytes in peripheral smear.[21] Imaging studies cannot differentiate KFD from other causes of lymphadenopathy and seldom provide any conclusive diagnostic results. Fine needle aspiration cytology of lymph node can be helpful in diagnosis, but its accuracy is only 56\%.[22] Diagnosis can be established by lymph node biopsy. Histological findings include distortion of normal nodal architecture. Nodules may be seen in cortex and paracortex with coagulative necrosis and abundant karyorrhectic debris. Other histopathological features include histiocytes in peripheral parts of necrotic areas, plasma cells may be present and neutrophils are usually absent. On immunohistochemical staining histiocytes expressing CD68, myeloperoxidase and CD4 are abundant. Plasmacytoid dendritic cells expressing CD123 are also seen. ${ }^{[23]}$

KFD is a usually a self-limiting condition. Treatment is mainly supportive. NSAIDS are used to alleviate pain and fever. Corticosteroids can be given in severe cases.[24] Other treatment options include hydroxychloroquine ${ }^{[25]}$ and intravenous immunoglobulins.[26] Relapse rate in KFD is about 3 - 4\%.[27]

Kikuchi-Fujimoto disease, although an uncommon cause of cervical lymphadenopathy and fever should be considered in differential diagnoses, as its treatment significantly differs from other causes of cervical lymphadenopathy. Lymph node biopsy can aid in early diagnosis of KFD and avoid unnecessary investigations and treatment.

\section{FINAL DIAGNOSIS}

Kikuchi-Fujimoto Disease.

\section{REFERENCES}

[1] Kikuchi M. Lymphadenitis showing focal reticulum cells hyperplasia with nuclear debris and phagocytosis: a clinicopathological study. Nippon Ketsueki Gakkai Zasshi 1972;35:379-80.

[2] Fujimoto Y, Kojima Y, Yamaguchi K. Cervical subacute necrotizing lymphadenitis. A New Clinicopathological Entity 1972;20:920-7.

[3] Yen A, Fearneyhough P, Raimer SS, et al. EBVassociated Kikuchi's histiocytic necrotizing lymphadenitis with cutaneous manifestations. J Am Acad Dermatol 1997;36(2 Pt 2):342-6.

[4] Chiu CF, Chow KC, Lin TY, et al. Virus infection in patients with histiocytic necrotizing lymphadenitis in Taiwan. Detection of Epstein-Barr virus, type I human T-cell lymphotropic virus and parvovirus B19. Am J Clin Pathol 2000;113(6):774-81.

[5] Hollingsworth HC, Peiper SC, Weiss LM, et al. An investigation of the viral pathogenesis of KikuchiFujimoto disease. Lack of evidence for Epstein-Barr virus or human herpesvirus type 6 as the causative agents. Arch Pathol Lab Med 1994;118(2):134-40.

[6] Hudnall SD, Chen T, Amr S, et al. Detection of human herpesvirus DNA in Kikuchi-Fujimoto disease and reactive lymphoid hyperplasia. Int J Clin Exp Pathol 2008;1(4):362-8.
[7] Labrador J, Aparicio MA, Santos-Briz A, et al. KikuchiFujimoto disease: a case supporting a role for human herpesvirus 7 involvement in the pathogenesis. Rheumatol Int 2013;33(12):3065-8.

[8] Zhang WP, Wang JH, Wang WQ, et al. An association between parvovirus B19 and Kikuchi-Fujimoto disease. Viral Immunol 2007;20(3):421-8.

[9] Heikens J, Tel W, van de Stadt J, et al. Kikuchi's lymphadenitis: report of a Yersinia enterocoliticaassociated case and an overview of aetiology and clinical outcome. Netherlands Journal of Medicine 1992;41(5-6):222-8.

[10] Charalabopoulos K, Papalimneou V, Charalabopoulos $\mathrm{A}$, et al. Brucella melitensis infection stimulates an immune response leading to Kikuchi-Fujimoto disease. In Vivo 2003;17(1):51-3.

[11] Chung JY, Sang WK, Han TH, et al. Detection of the Bartonella henselae gene sequence in lymph nodes of children with Kikuchi's disease. Pediatrics 2005;115(4):1112.

[12] Aydogan T, Kanbay M, Uraldi C, et al. Kikuchi Fujimoto disease secondary to Entamoeba histolytica: case report. Journal of Infection 2006;53(4):e171-e3.

[13] Bosch X, Guilabert A, Miquel R, et al. Enigmatic Kikuchi-Fujimoto disease: a comprehensive review. Am J Clin Pathol 2004;122(1):141-52.

[14] Sopeña B, Rivera A, Vázquez-Triñanes C, et al. Autoimmune manifestations of Kikuchi disease. Semin Arthritis Rheum 2012;41(6):900-6.

[15] Tanaka T, Ohmori M, Yasunaga S, et al. DNA typing of HLA class II genes (HLA-DR, -DQ and -DP) in Japanese patients with histiocytic necrotizing lymphadentis (Kikuchi's disease). Tissue Antigens 1999;54(3):24653.

[16] Lin HC, Su CY, Huang CC, et al. Kikuchi's disease: a review and analysis of 61 cases. Otolaryngol Head and Neck Surg 2003;128(5):650-3.

[17] Krishnappa J, Reddy BD, Harsha PJ, et al. Familial Kikuchi-Fujimoto disease. J Clin Sci Res 2015;4:40-4. http://dx.doi.org/10.15380/2277-5706.JCSR.13.077.

[18] Seno A, Torigoe R, Shimoe K, et al. Kikuchi's disease (histiocytic necrotizing lymphadenitis) with cutaneous involvement. J Am Acad Dermatol 1994;30(3):504-6.

[19] Kucukardali Y, Solmazgul E, Kunter E, et al. KikuchiFujimoto disease: analysis of 244 cases. Clin Rheumatol 2007;26(1):50-4.

[20] Cheng CY, Sheng WH, Lo YC, et al. Clinical presentations, laboratory results and outcomes of patients with Kikuchi's disease: emphasis on the association between recurrent Kikuchi's disease and autoimmune diseases. J Microbiol Immunol Infect 2010;43(5):366-71.

[21] Kuo TT. Kikuchi's disease (histiocytic necrotizing lymphadenitis). A clinicopathologic study of 79 cases with an analysis of histologic subtypes, immunohistology and DNA ploidy. Am J Surg Pathol 1995;19(7):798-809.

[22] Tong TR, Chan OW, Lee KC. Diagnosing Kikuchi disease on fine needle aspiration biopsy: a retrospective study of 44 cases diagnosed by cytology and 8 by histopathology. Acta Cytol 2001;45(6):953-7. 
[23] Gordon JK, Magro C, Lu T, et al. Overlap between systemic lupus erythematosus and Kikuchi Fujimoto disease: a clinical pathology conference held by the Department of Rheumatology at Hospital for Special Surgery. HSS J 2009;5(2):169-77.

[24] Jang YJ, Park KH, Seok HJ. Management of Kikuchi's disease using glucocorticoid. J Laryngol Otol 2000;114(9):709-11.

[25] Rezai K, Kuchipudi S, Chundi V, et al. Kikuchi-Fujimoto disease: hydroxychloroquine as a treatment. Clinical Infectious Diseases 2004;39(12):e124-e6.
[26] Noursadeghi M, Aqel N, Gibson P, et al. Successful treatment of severe Kikuchi's disease with intravenous immunoglobulin. Rheumatology (Oxford) 2006;45(2):235-7.

[27] De Andre SA, Soares JM, De Sa Santos MH, et al. Kikuchi-Fujimoto disease: three case reports. Sao Paulo Med J 2010;128(4):232-5. 